\title{
Orthographic cues to lexical stress: Effects on naming and lexical decision
}

\author{
MICHAEL H. KELLY, JOANNA MORRIS, and LAURA VERREKIA \\ University of Pennsylvania, Philadelphia, Pennsylvania
}

\begin{abstract}
Words whose spellings represent regular phonemic patterns, such as mint, show advantages in naming and lexical decision tasks over words, such as pint, that have exceptional relations between orthographic and phonemic patterns. We have extended such phenomena to the domain of lexical stress, by showing that disyllabic words whose spellings are consistent with their stress are easier to process than words whose spellings are misleading about stress. Such words are named more quickly and are pronounced with incorrect stress less often (Experiment 1). They are also classified more quickly and accurately in lexical decision tasks (Experiments 2 and 3). These results indicate that literate speakers have learned orthographic correlates to lexical stress in English. In addition, the similarities between results in the phonemic and prosodic domains indicate that models of reading developed for the former could be extended to the latter area.
\end{abstract}

The phonological structure of a word consists of its phonemic composition and stress pattern. Both structures are important for pronouncing a word correctly, yet English spelling appears to represent only phonemic information. Thus, the English orthography does not contain a symbol like the ' used by dictionaries to mark lexical stress patterns. However, certain letter arrangements are correlated with stress. For example, a survey of the American Heritage Electronic Dictionary revealed that $91 \%$ of disyllabic words ending in et, such as comet and sonnet, have stress on the first syllable (a trochaic stress pattern), whereas $96 \%$ of disyllabic words ending in ette, such as roulette and dinette, have stress on the second syllable (an iambic stress pattern).

The et/ette example is not an isolated case, as English contains many other orthographic cues to stress whose predictiveness can be verified through analyses of the English lexicon (Verrekia \& Kelly, 1996). Table 1 presents some of these cues and how they operate in disyllabic words, which will be the focus of this paper. In particular, the table presents the percentage of words with certain spelling patterns that have trochaic stress, as determined by a survey of the American Heritage Electronic Dictionary. Two generalizations can be induced from these patterns. First, orthographic cues to stress are located in the second rather than the first syllables of disyllabic words. Thus, the spellings of trochaic discus and iambic discuss differ

This research was supported by NIH Grant R29 HD23385 and was submitted to the University of Pennsylvania in partial fulfillment of the second author's doctoral requirements. Thanks to Lila Gleitman, John Trueswell, Virginia Richards, and two anonymous reviewers for helpful comments on this work. Address reprint requests to M. Kelly, Department of Psychology, University of Pennsylvania, 3815 Walnut Street, Philadelphia, PA 19104-6196(e-mail: kelly@psych.upenn.edu).

-Accepted by previous editor, Geoffrey R. Loftus only in the last syllable. Second, stress patterns for iambic words seemed to be orthographically marked, in the sense that more letters are used to represent phonemic information than are necessary. There are some exceptions to this trend, as in the ene/een case shown in the table, but the generalization applies to most of the spelling contrasts. Thus, the final /s/ in discuss could be represented adequately by a single $s$, as it is in discus. This asymmetry reflects the overwhelming predominance of trochaic stress in English (see, e.g., Cutler \& Carter, 1987; Kelly \& Bock, 1988). For instance, over $90 \%$ of all disyllabic nouns in English have trochaic stress. Given such high baserate levels, any orthographic cues for trochaic stress would have marginal utility. Indeed, the orthographic patterns in the trochaic column in Table 1 do not differ very much from the high background level of trochaic stress in English. In contrast, spelling cues indicative of the rarer iambic pattern would be helpful, and English appears to encode this atypical prosody by incorporating more letters into the second syllable. This method of representing prominence is also used in other areas of English orthography. For example, proper names are sometimes padded with extra letters, as shown by comparing names such as Kidd, Penn, and Sharpe with their common word homophones kid, pen, and sharp (Carney, 1994; Smith, Baker, \& Groat, 1982).

The use of string length to represent stress or other types of prominence is subject to an important constraint. In particular, the phonemic structure of the relevant syllable cannot be distorted by adding additional letters. This constraint accounts for the fact that many orthographic cues to stress involve doubling a letter. Thus, the extra $s$ in discuss does not alter the identity of the final phoneme and so can be used to represent other information. However, English is well known for the various ways in which it can represent a phoneme or phonemic sequence (Carney, 1994; Venezky, 1970). Hence, there are many poten- 
Table 1

Spelling Patterns Associated With Trochaic and Iambic Stress in English, the Percentage of Words With Each Spelling Pattern That Have Trochaic Stress (\%T), and Word Examples

\begin{tabular}{lrllll}
\hline Trochaic & $\% \mathrm{~T}$ & Example & lambic & $\% \mathrm{~T}$ & Example \\
\hline -um & 100 & Dictum & -umb & 0 & Succumb \\
-c & 95 & Basic & -que & 0 & Baroque \\
-el & 86 & Gravel & -elle & 0 & Gazelle \\
-et & 91 & Rivet & -ette & 4 & Roulette \\
-as & 84 & Canvas & -asse & 17 & Crevasse \\
-o & 98 & Plato & -eau & 26 & Plateau \\
-u & 86 & Bantu & -oo & 53 & Bamboo \\
-y & 99 & Trusty & -ee & 54 & Trustee \\
-or & 99 & Gator & -ore & 60 & Galore \\
-ene & 69 & Benzene & -een & 17 & Baleen \\
\hline
\end{tabular}

tial orthographic resources for marking stress in English, as is illustrated in Table 1.

Although few literate speakers are consciously aware of these relations between stress and spelling, research has shown that they have implicit knowledge of them. Smith and Baker (1976) asked subjects to read disyllabic pseudowords aloud and examined how spelling affected stress placement. Pseudoword pairs were constructed that differed minimally in spelling, with one member of each pair ending in a double letter (e.g., nuvit vs. nuvitt). Pseudowords received iambic stress more often when they ended in double letters. Verrekia and Kelly (1996) extended this research in two ways. First, they examined spelling in addition to reading and found that subjects used more letters to represent the second syllable of a disyllabic pseudoword when it was stressed rather than unstressed. Furthermore, the subjects were able to adjust spelling while preserving the phonemic structure of the syllable. Second, Verrekia and Kelly included spelling patterns other than letter doubling and found that English speakers were sensitive to these patterns as well. For example, disyllabic pseudowords that ended in $/ \mathrm{k} /$ were more likely to be pronounced with iambic stress if the final phoneme was spelled que rather than $k$.

The purpose of this paper is to examine the role of orthographic cues to stress in the naming and identification of actual English words. These experiments will exploit the fact that orthographic patterns are only probabilistically related to stress. For example, although ette tends to be associated with iambic stress and $e t$ with trochaic stress, exceptions exist, such as palette and cadet. A similar phenomenon occurs in the relationship between orthography and phonemic structure in English. Many orthographic patterns map onto standard phonemic sequences but nonetheless contain some violations. For instance, int is generally pronounced/Int/, as in mint, tint, hint, and sprint, but this same pattern is pronounced / aint / in pint. On analogy with research in the orthography-phoneme domain, we will call words like roulette regular, since their orthography-stress relation conforms with the standard patterns in English. Words, like palette, that violate these standards will be called exceptions.
Many experiments on orthography-phoneme relationships have found processing advantages for regular words. We will concentrate here on advantages observed in naming and lexical decision tasks. First, when subjects are asked to read words aloud as quickly as possible, regular words are named more quickly than exception words (see, e.g., Seidenberg, Waters, Barnes, \& Tanenhouse, 1984; Taraban \& McClelland, 1987; Waters \& Seidenberg, 1985). Second, when subjects in lexical decision tasks are asked to classify a string of letters as a word or a nonword, they are faster and more accurate at classifying regular words than exception words (see, e.g., Parkin, 1982; Waters \& Seidenberg, 1985). The naming and lexical decision tasks correspond with two important aspects of reading. First, reading a word aloud requires that a phonological representation be accessed or constructed. Results from naming studies indicate that these processes occur more quickly for regular words. Second, successful reading comprehension requires that words be recognized and their meanings retrieved from memory. To the extent that the construction of phonological representations in reading contributes to these goals, words with consistent mappings between orthography and phonology should show advantages over words with inconsistent mappings. In the extreme, if an exception word such as pint is encoded phonologically as / pint/, word identification will not only be delayed but will fail, since no such word exists. Subjects would then mistakenly classify exception words as nonwords in lexical decision tasks.

The same rationale that has been used to study the relations between orthography and phonemic structure can be extended to the relations between orthography and stress structure. Thus, words whose spellings are consistent with their stress patterns should show advantages, in naming and lexical decision tasks, over words whose spellings are inconsistent with their stress patterns. If verified in the experiments reported here, such results would suggest that the same processes used to determine the phonemic representation of a written word are also involved in stress assignment. Hence, the scope of issues and models in reading research would be considerably broadened.

\section{EXPERIMENT 1 Naming}

In this experiment, the subjects read disyllabic words aloud, with naming latency and accuracy in stress assignment serving as dependent measures. The words had either iambic or trochaic stress and either contained or lacked orthographic patterns indicative of iambic stress. For instance, the subjects were asked to read iambic words like cassette and cadet. The former item contains an orthographic pattern, ette, associated with iambic stress, whereas the latter does not. If orthography is used to determine stress assignment, subjects should be faster to name words like cassette than words like cadet. In addition, they should be less likely to read such words with the 
Table 2

Mean Frequencies and Lengths in Characters of Words (With Standard Deviations) in Experiments 1 and 2

\begin{tabular}{llllll} 
& \multicolumn{2}{c}{ Frequency } & & \multicolumn{2}{c}{ Length } \\
\cline { 5 - 6 } \multicolumn{1}{c}{ Condition } & $M$ & $S D$ & & $M$ & $S D$ \\
\hline Marked iambic & 1.5 & 1.9 & 6.9 & 1.0 \\
Unmarked iambic & 2.6 & 3.9 & 5.5 & 0.9 \\
Marked trochaic & 3.4 & 4.6 & 7.0 & 1.2 \\
Unmarked trochaic & 4.6 & 5.9 & 6.2 & 1.2 \\
\hline
\end{tabular}

incorrect trochaic stress pattern. The predictions are reversed for trochaic words like palette and pellet. The ette pattern in palette is a misleading cue to stress, since it is usually associated with iambic words. If the subjects nonetheless weigh this information in determining stress assignment, they should be slower to name words like palette than words like pellet. They should also be more likely to pronounce these words with an incorrect iambic prosody.

\section{Method}

Subjects. Sixteen members of the University of Pennsylvania community were paid for their voluntary participation in the experiment. All the subjects were native speakers of English.

Materials. Sixty-four disyllabic words were selected for the experiment. To control for correlations between stress and grammatical class in English (Kelly, 1992), the primary uses of all words were as nouns or proper nouns, as determined by the Francis and Kučera (1982) word frequency norms. The words were divided equally into four categories formed by crossing the factors of word stress (iambic or trochaic) and orthography (marked or unmarked for iambic stress). At the most general level, an orthographic pattern was considered to be a mark for iambic stress if it could have been spelled with a shorter orthographic sequence while still preserving phonemic structure. For example, in words with final eau, $t t e$, and aine, $/ \mathrm{o} /, / \mathrm{t} /$, and /ein/ could have been accurately represented with the shorter spellings $o, t$, and ain. In addition, the specific patterns used in the experiments had verified associations with iambic stress, as determined by experimentation (Smith \& Baker, 1976) or by experimentation coupled with surveys of the English lexicon (Verrekia \& Kelly, 1996). These patterns included letter doubling (e.g., the double $l$ in Cornell), silent $e$ addition (e.g., $m i$ graine), letter doubling plus silent $e$ addition (e.g., the ffe in giraffe), and idiosyncratic spellings that predict iambic stress (e.g., the que in boutique). Orthographic markers for iambic stress always appeared in the second syllable.

Words with the same stress pattern were arranged into yoked pairs, with one member of each pair having orthographic support for iambic stress and the other lacking it (e.g., plateau and pastel among iambic words and levee and lever among trochaic words). The words in each pair began with the same phoneme in order to control for differences in the ease and speed with which phonemes trigger a voice key. They were also selected to be roughly similar phonologically in the rest of the word.

Table 2 shows the mean frequencies (Francis \& Kučera, 1982) and lengths in characters of the words in the four conditions of the experiment. The general low frequency of the words was a deliberate constraint on the materials. Prior research in the orthographyphoneme domain has found that the advantages for regular words over exception words are inversely related to frequency (Seidenberg et al., 1984). If this pattern applies to the mapping between orthography and stress, similar processing advantages for words with reliable cues to stress would be found most strongly with lowfrequency words.
Both the frequencies and the lengths of the words were submitted to separate $2 \times 2$ analyses of variance (ANOVAs), with the factors of stress (iambic or trochaic) and spelling (marked or unmarked for iambic stress). No significant relations were found between frequency and the factors of stress, spelling, or their interaction. In the word length analysis, only the main effect of spelling was significant $[F(1,30)=32.87, p<.0001]$, with words marked for iambic stress containing more letters (mean $=7.0$ ) than words not marked for iambic stress (mean $=5.9$ ). Of course, this difference was expected, since English encodes stress through string length. However, any advantage for shorter words (see, e.g., Hudson \& Bergman, 1985) would favor unmarked iambic words over marked iambic words, contrary to the predictions of the experiment. The complete set of words used in the experiment is provided in Appendix A.

Procedure. The experiment was run on an Apple Macintosh computer. The subjects were instructed that they would be presented with a series of words on the computer monitor that they would be asked to read aloud as quickly and accurately as possible. The subjects seated themselves at a comfortable viewing distance from the monitor and had a microphone attached to their shirt or sweater. This microphone was connected to the computer and was used to detect the onset of the subject's response, relative to the onset of word presentation. The subjects first went through a practice set of 10 monosyllabic words, followed by the 64 critical items, with the latter presented in a random order. Each word was presented at the center of the computer screen in 18 point bold courier font. The first letter in all the words was capitalized so that there would be no distinction between proper nouns and common nouns. In addition to measuring naming latencies, responses were tape recorded so that stress assignments could be examined

\section{Results and Discussion}

The first and second authors classified the stress patterns for each word as trochaic or iambic and agreed on $96 \%$ of their judgments. In order to be conservative in the analyses, a pronunciation was counted as a stress error only when both raters classified it as such. Figures 1 and 2 show the mean proportions of stress errors and naming latencies for the four conditions of the experiment, and Appendix A presents individual values for each word. Only words with correct stress pronunciations were in-

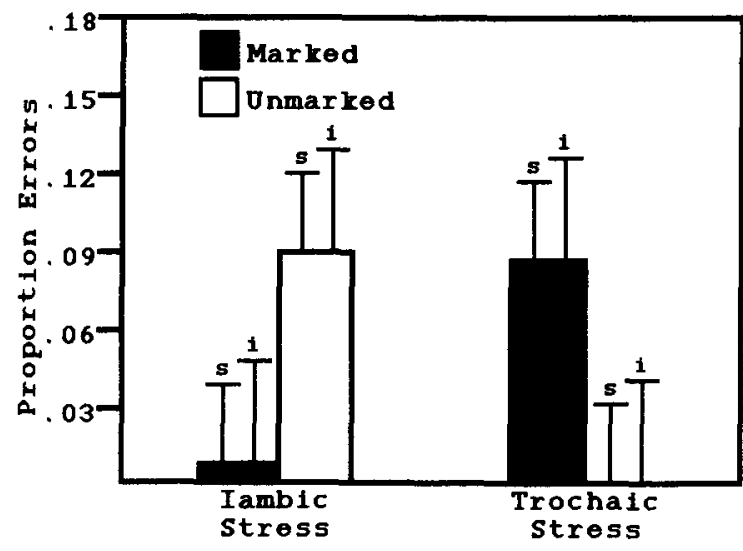

Figure 1. Mean proportion of words pronounced with incorrect stress, as a function of stress and spelling, in Experiment 1. Confidence intervals in this figure and others are based on the within-subjects (s) and within-items (i) variability, as discussed in Loftus and Masson (1994). 


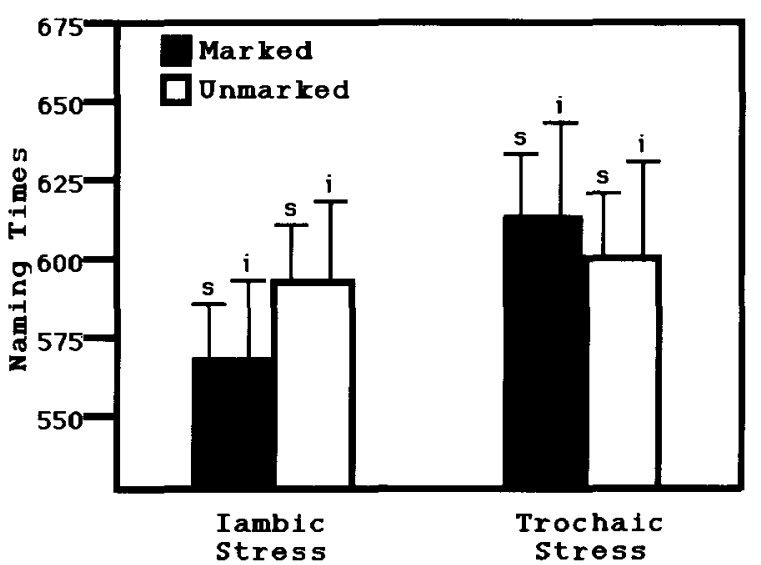

Figure 2. Mean correct naming times, in milliseconds, as a function of stress and spelling, in Experiment 1.

cluded in the latency data. In addition, all response times greater than two standard deviations above a subject's overall mean latency were replaced by the two standard deviation value. ANOVAs were conducted on the naming latency and stress error data, with subjects and items as random variables. The analyses fit a $2 \times 2$ design, with the factors of stress (trochaic or iambic) and spelling (marked or unmarked for iambic stress).

The major prediction in the experiment was that words whose spellings are consistent with their stress (marked iambic words and unmarked trochaic words) should be read more quickly and accurately than words whose spellings are misleading about their stress (unmarked iambic words and marked trochaic words). Thus, words with orthographic markings for iambic stress should facilitate naming for iambic words but hinder naming for trochaic words. This prediction was confirmed statistically through a significant interaction between stress and spelling in the error data [subjects, $F(1,15)=41.83$; items, $F(1,30)=$ 16.48 ; both $p \mathrm{~s}<.0005]$. The interaction in the latency data was significant across subjects $[F(1,15)=5.32, p<$ $.04]$ but marginal across items $[F(1,30)=3.32, p<.08]$. Words with consistent spelling and stress patterns were named in $584 \mathrm{msec}$ and were pronounced with incorrect stress only $0.4 \%$ of the time. In contrast, words with inconsistent spelling and stress patterns were named in $602 \mathrm{msec}$ and were pronounced with incorrect stress $8.8 \%$ of the time. The predicted patterns appeared when iambic and trochaic words were examined separately (see Figures 1-2), although the effects were insignificant in some analyses. The naming latency advantage for marked iambic words over unmarked iambic words was significant across subjects $[t(15)=2.38, p<.04]$ but not across items $[t(15)=1.61, p>.10]$. However, the accuracy advantage was significant across both subjects $[t(15)=5.55, p<$ $.0001]$ and items $[t(15)=3.32, p<.005]$. Trochaic words were named more slowly and less accurately when they had spellings indicative of iambic stress than when they did not. The latency difference was not significant $(p>$
.30 across both subjects and items). However, the error difference was significant across both subjects $[t(15)=$ $5.06, p<.0002]$ and items $[t(15)=2.59, p<.03]$.

No other significant effects appeared in the overall ANOVAs. There was a marginally significant latency advantage for iambic words $(581 \mathrm{msec})$ over trochaic words [606 msec; subjects, $F(1,15)=3.44$; items, $F(1,30)=$ $3.03 ; p \mathrm{~s}<.10]$. However, this main effect of stress did not appear in the error data $(F \mathrm{~s}<0.50)$, in both subjects and items analyses). Indeed, if anything, iambic words received incorrect stress more often than did trochaic words ( $4.8 \%$ vs. $4.3 \%$ errors).

This naming experiment indicates that literate English speakers not only use orthography to determine the phonemic representations of written words but also to determine their stress patterns. Furthermore, the contrast between spelling patterns that are regular or consistent with their pronunciation and patterns that are misleading or inconsistent, which has been so fruitfully applied to phonemic encoding, can be extended to prosodic encoding. The next experiment will test whether this similarity can be extended to the lexical decision task.

\section{EXPERIMENT 2 Lexical Decision}

The naming advantage found for marked iambic and unmarked trochaic words does not entail that they were identified more easily than their unmarked iambic and marked trochaic counterparts. Rather, the subjects could have relied on their knowledge of English orthography, including its relation with stress, to construct phonological representations for the materials. These representations would be more accurate for words that had spellings consistent with their stress patterns, and so stress errors would occur less often for such items. The process of word identification could have been occurring in parallel on the basis of the visual characteristics of the stimuli. The slow latencies for unmarked iambic and marked trochaic words, then, could have been caused by conflicts between orthographically determined phonological representations and the actual representations retrieved as part of word identification. However, the latter process may have been unaffected by consistencies between spelling and stress. Thus, the subjects may have recognized baton just as easily as boutique, even as they pronounced it more slowly or with the incorrect stress pattern.

Table 3

Mean Frequencies and Lengths in Characters of Words (With Standard Deviations) in Experiment 3

\begin{tabular}{|c|c|c|c|c|}
\hline \multirow[b]{2}{*}{ Condition } & \multicolumn{2}{|c|}{ Frequency } & \multicolumn{2}{|c|}{ Length } \\
\hline & $M$ & $S D$ & $M$ & $S D$ \\
\hline Marked iambic & 7.8 & 25.3 & 7.1 & 0.9 \\
\hline Unmarked iambic & 9.6 & 16.7 & 5.3 & 0.8 \\
\hline Marked trochaic & 11.3 & 18.7 & 6.8 & 1.1 \\
\hline Unmarked trochaic & 7.7 & 8.5 & 5.4 & 1.0 \\
\hline
\end{tabular}




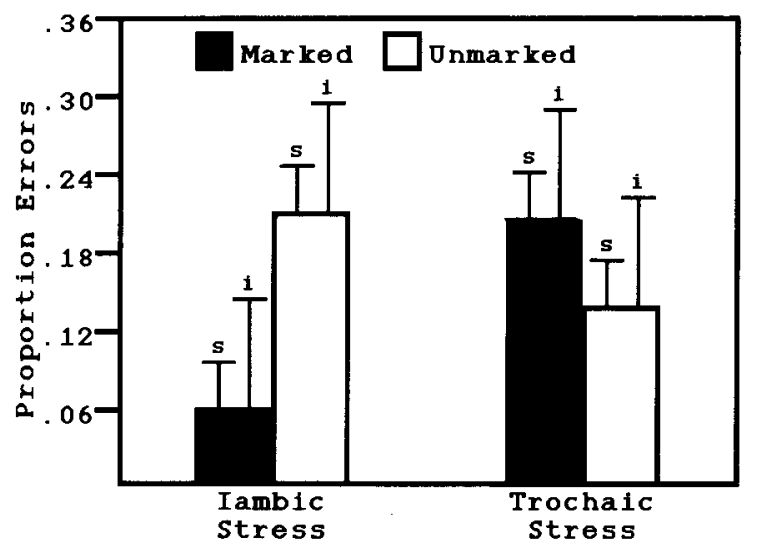

Figure 3. Mean proportion of words classified incorrectly as nonwords, as a function of stress and spelling, in Experiment 2.

In order to test whether inconsistent mappings between orthography and stress can actually hinder word identification, Experiment 2 used the lexical decision task, which requires that the word status of each stimulus be explicitly determined. However, this determination can be made without actually identifying individual words if some other characteristic, correlated with lexical structure, discriminates the word stimuli from the nonword foils. For instance, if the nonword stimuli consist of illegal orthographic sequences, subjects can use visual information to distinguish words from nonwords (Seidenberg \& McClelland, 1989). In order to encourage the subjects to construct and use phonological representations to perform this task, only pronounceable nonwords were used as foils.

\section{Method}

Subjects. Sixteen members of the University of Pennsylvania community were paid for their voluntary participation in the experiment. All the subjects were native speakers of English.

Materials. The 64 target words from the naming experiment were also used here. These words were supplemented with an additional set of 96 nonwords and 32 real words. Thus, there were 192 total stimuli in the experiment, consisting of 96 real words and 96 nonwords. Half of the nonwords and half of the nontarget real words contained one syllable, whereas the other half contained three syllables. This composition of nonwords does permit a decision strategy whereby all disyllabic items would be classified as words. Nonetheless, we decided that only the target items would contain two syllables, because we would not be able to control or monitor stress patterns assigned to disyllabic nonwords, and any biases in these stress assignments might contaminate results with the target words (e.g., through stress priming). Furthermore, the spellings given to disyllabic nonwords might have created undesirable effects on the treatment of the target words. All of the nonwords were pronounceable, so that subjects could not use purely visual information to distinguish real words from nonwords but would be induced to construct a phonological representation for each stimulus and match it to existing words in their lexicons. A list of the nonwords is presented in Appendix B.

Procedure. The stimuli were presented in the same manner as those in the first experiment, except that the subjects were now instructed to decide whether each letter string did or did not correspond with a word. Subjects registered word and nonword judgments by pressing the command and option buttons on the computer keyboard.

\section{Results and Discussion}

The subjects classified nonwords correctly $89 \%$ of the time and with a mean correct latency of $917 \mathrm{msec}$. Figures 3 and 4 show the mean error proportion and latencies in classifying the target items as words, and Appendix A presents values for each word individually. Incorrect classifications were excluded from the latency data. In addition, response times greater than two standard deviations above a subject's overall mean were replaced by the two standard deviation value. The same ANOVA designs as those used in the first experiment were also used here.

As predicted, orthographic patterns indicative of iambic stress facilitated lexical decisions to iambic words but tended to interfere with lexical decisions to trochaic words. This pattern was confirmed statistically through significant interactions between stress and spelling in the latency [subjects, $F(1,15)=5.47$; items, $F(1,30)=6.49 ; p$ s $<$ .03 ] and error [subjects, $F(1,15)=36.10$; items, $F(1,30)=$ $7.38 ; p \mathrm{~s}<.02]$ data. Overall, words with reliable orthographic information about stress (marked iambic words and unmarked trochaic words) were classified in $790 \mathrm{msec}$ with a $10 \%$ error rate, whereas words with misleading orthographic information about stress (unmarked iambic words and marked trochaic words) were classified in $844 \mathrm{msec}$ with a $21 \%$ error rate. The advantage of marked iambic words over unmarked iambic words was significant across both subjects $[t(15)=6.84, p<.0001]$ and items $[t(15)=2.86, p<.015]$ in the error data. The latency advantage for marked iambic words was significant across subjects $[t(15)=2.75, p<.02]$ and marginally significant across items $[t(15)=2.01, p<.07]$. In contrast, the slight timing and accuracy advantages for unmarked trochaic words over their marked counterparts were generally not significant. The only exception was a significantly lower error rate for unmarked trochaic words in the subjects analysis $[t(15)=2.22, p<.05]$.

In addition to the predicted spelling $\times$ stress interaction, the main effect of stress was also significant in the latency analyses. In particular, iambic words were classified more quickly than trochaic words [790 vs. $845 \mathrm{msec}$; subjects,

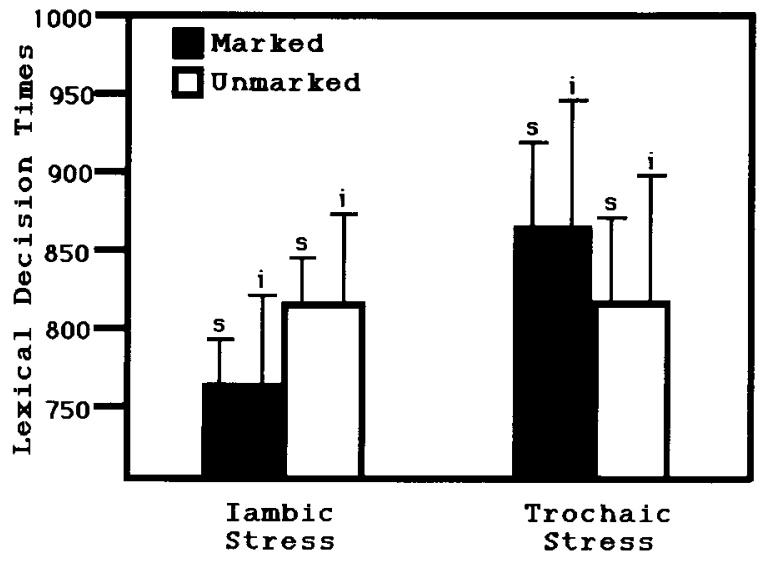

Figure 4. Mean correct lexical decision times in milliseconds, as a function of stress and spelling, in Experiment 2. 
$F(1,15)=7.93$; items, $F(1,30)=5.27 ; p s<.03]$. A similar latency advantage for iambic words appeared in Experiment 1 , although it was not as strong statistically and even reversed direction in the error data. It is not clear why this iambic advantage occurred. Given the dominance of trochaic stress in English, one would have expected that words with this stress pattern would have been processed more easily. Perhaps the relatively high proportion of iambic words in the experiments led the subjects to prepare for such stress patterns more than they normally would.

In sum, the lexical decision results were very similar to the naming results. Spelling patterns associated with iambic stress significantly facilitated performance for iambic words but tended to hinder performance for trochaic words. In both experiments, the predicted patterns were stronger for iambic words than for trochaic words. This trend may indicate that orthographic information is less important in the pronunciation of trochaic words, which follows from the high frequency of this pattern in English word prosody. If confirmed in later studies, it may provide a prosodic example of the interaction between frequency and orthographic regularity that has been repeatedly found in the phonemic domain (see, e.g., Waters $\&$ Seidenberg, 1985). Just as misleading spellings have a relatively small impact on the processing of highfrequency words, so they may also have less influence on the processing of high-frequency stress patterns.

\section{EXPERIMENT 3 Lexical Decision Replication}

Although the results from Experiment 2 suggest that lexical access could be impeded by misleading orthographic cues to stress, there is an important alternative explanation that must be considered. Some of the words used in the experiment, such as trochee and mandrill, may have been so unfamiliar to the subjects that they were often treated as pseudowords. Hence, error rates and classification times may have been high for those items, not because of their spelling patterns, but because of their extreme unfamiliarity. The high error rates in some of the conditions from Experiment 2 (greater than 20\%) and the especially high error rates for particular items lend credence to this possibility.

In order to address this problem, we replicated the lexical decision experiment with modified materials. In particular, we replaced items of questionable familiarity, such as trochee, with more familiar words, such as coffee. Of course, this change broke the yoked relationship between trochee and trojan established in Experiments 1 and 2, because coffee and trojan do not begin with the same phoneme. However, this matching on initial phoneme was instituted primarily for the naming experiment, in order to control for variation in the speed with which different phonemes trigger a voice key. Such matching is not necessary in the lexical decision task, since the correct re- sponse is identical for all the words. Hence, in selecting new materials for Experiment 3, we did not attempt to match the new items with particular old items. Instead, we broke all yoked relationships in the materials and used a completely between-items design. In order to compensate for the greater item variability that is likely in this design, we added eight new words to each condition, thus increasing the items per cell from 16 to 24 .

\section{Method}

Subjects. Eighteen native English speakers were paid for their voluntary participation.

Materials. Twelve words from the stimulus set used in Experiments 1 and 2 were replaced with items that we judged to be more familiar. The new words (with the replaced items in parentheses) were: Cartel (Collage), Motel (Guffaw), Bernard (Gerard), Brazil (Rochel), Cigar (Chiffon), Coffee (Trochee), Sheriff(Levee), Compass (Mandrill), Turtle (Mandrake), Halo (Furrow), Velvet (Ver$\mathrm{min}$ ), and Bonnet (Ingot). Six other words were replaced with items whose spellings were more closely related to spelling alternations associated with stress, such as el-elle, o-eau, $u-o o$, and final consonant doubling. These new words (and the items they replaced) were: Michelle (Suspense), Bureau (Impulse), Tariff (Hardship), Menu (Lever), Plato (Rosemont), and Susan (Ronald). The remaining 46 words from the stimuli used in the first two experiments were retained here. These were supplemented with 32 new words, divided equally across the experimental conditions. Thus, there were 24 words in each condition formed by crossing the factors of stress (iambic or trochaic) and spelling (marked or unmarked). The complete stimulus list is provided in Appendix C. The pseudoword foils and monosyllabic real word fillers from Experiment 2 were also used here.

Table 3 shows the mean frequencies (Francis and Kučera, 1982) and lengths in characters of the words in the four conditions of the experiment. Each variable was examined in a $2 \times 2$ ANOVA, with the factors of stress and spelling. No significant main effects or interactions were found involving the frequency variable (all $p \mathrm{~s}>$ .50). However, a comparison of Tables 2 and 3 shows that the mean frequencies for Experiment 3 are higher than those for Experiments 1 and 2 , which is consistent with the attempt to select more familiar words for this study. Furthermore, an examination of Table 3 and Appendix $C$ will reveal that, if anything, the higher frequency words tend to appear in conditions involving misleading orthographic cues to stress. Hence, any processing advantage for higher frequency words would work against the experimental predictions. The only significant effect for the word length analysis was the expected main effect of spelling $[F(1,92)=67.99, p<.0001]$, with words marked for iambic stress containing more letters (mean $=$ 7.0 ) than did words not marked for iambic stress (mean $=5.3$ ).

Procedure. The procedure was the same as that described for Experiment 2 .

\section{Results and Discussion}

Overall, the subjects classified the target words correctly $93 \%$ of the time and with a mean correct latency of $671 \mathrm{msec}$. In contrast, the corresponding values from Experiment 2 were $85 \%$ mean classification accuracy and 817 msec mean correct latency. Furthermore, mean classification accuracy was greater than $90 \%$ in all four conditions of the experiment, whereas some conditions of Experiment 2 had accuracy levels of less than $80 \%$. This combination of increased accuracy and decreased latency indicates that we were successful in selecting 


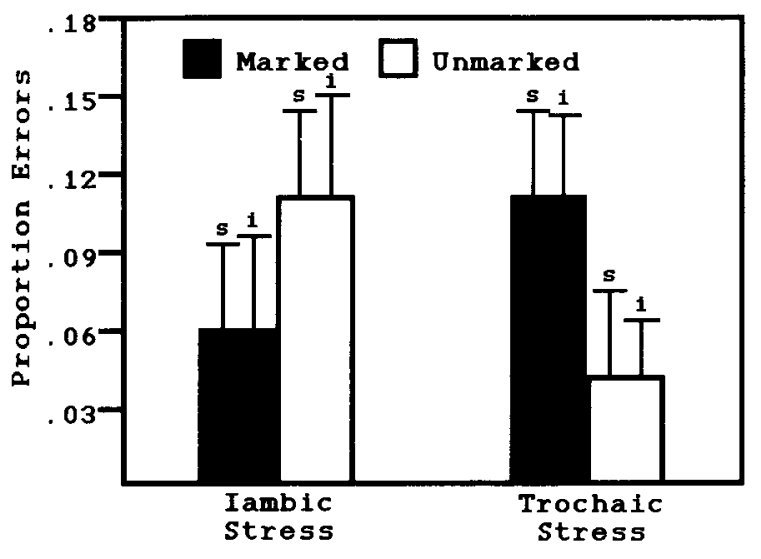

Figure 5. Mean proportion of words classified incorrectly as nonwords, as a function of stress and spelling, in Experiment 3.

more familiar words for the experiment. This conclusion is further supported by the fact that the pseudowords were classified accurately $91 \%$ of the time and with a mean latency of $725 \mathrm{msec}$. Hence, the superior performance on the target words was not purchased by inferior performance on the pseudowords. Indeed, performance on the pseudowords was better in Experiment 3 than in Experiment 2, which suggests that the greater familiarity of the target words sharpened the distinction between pseudowords and real words.

Figures 5 and 6 show the mean error proportions and latencies in classifying the target items as words, and Appendix $C$ presents values for each word individually. Incorrect classifications were excluded from the latency data. In addition, response times greater than two standard deviations above a subject's overall mean were replaced by the two standard deviation value. The subjects analysis followed the same ANOVA design as that in Experiment 2 . However, the items analysis fit a completely between-items design.

As in the prior experiments, the major prediction was supported, as orthographic patterns indicative of iambic stress interfered with responses made to trochaic words but tended to facilitate responses to iambic words. This pattern was confirmed statistically through significant interactions between stress and spelling in both the latency [subject, $F(1,17)=23.15$; items, $F(1,92)=6.09 ; p$ s $<.02$ ] and error [subject, $F(1,17)=6.77$; items, $F(1,92)=5.41$; $p s<.03$ ] data. Overall, words with reliable orthographic cues to stress (marked iambic words and unmarked trochaic words) were classified in $656 \mathrm{msec}$ with a $5 \%$ error rate, whereas words with misleading orthographic cues to stress (unmarked iambic words and marked trochaic words) were classified in $686 \mathrm{msec}$ with a $9 \%$ error rate. Both the latency and the error advantages for unmarked over marked trochaic words were significant across subjects [latency, $t(17)=5.46$; errors, $t(17)=2.19 ; p \mathrm{~s}<.05$ ] and items [latency, $t(46)=2.99$; errors, $t(46)=2.11 ; p \mathrm{~s}<$ $.05]$. Although marked iambic words were classified more quickly and accurately than unmarked trochaic words, these predicted advantages were not significant. In Experiments 1 and 2, the results were stronger for iambic items. Given these differences among the experiments, we cannot, at this time, maintain our earlier view that orthographic cues to stress might affect processing of iambic more than trochaic words because the former stress pattern is less frequent in English. This issue will have to be addressed more fully in future research.

In sum, the results of this experiment replicated the major patterns found in Experiments 1 and 2. Indeed, the predicted interaction between stress and spelling was consistently significant in both the error and latency data in all three experiments. Although the results were not consistently significant when trochaic and iambic items were considered separately, the patterns were in the predicted direction in every case. Thus, mean error rates and latencies for marked iambic words were always lower than the corresponding values for unmarked iambic words. Similar advantages for unmarked over marked trochaic words appeared in every comparison. Taken together, the three experiments make a strong case for our claims that orthographic cues to stress are learned and that words with reliable orthographic cues to stress are easier to process than words with misleading cues.

\section{GENERAL DISCUSSION}

Our experiments indicate that the concept of orthographic consistency can be extended from the phonemic domain to the prosodic domain. Words whose orthography is consistent with their stress or phonemic structure are processed more easily than words whose orthography is misleading about these phonological properties. This similarity suggests that models of reading developed for phonemic structure could be generalized to stress structure, since at least some of the same empirical phenomena occur in both areas. Indeed, if other similarities are identified in future research, reading models would be disfavored if they could not account for results from both the phonemic and the stress domains.

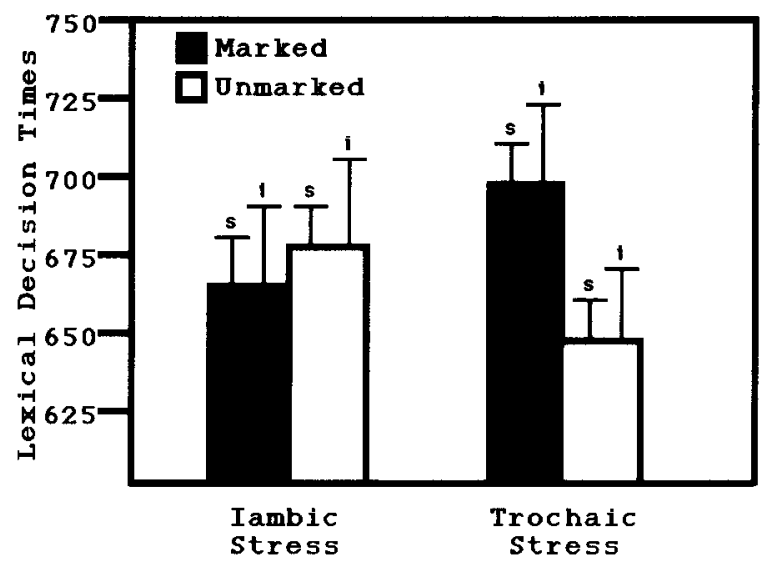

Figure 6. Mean correct lexical decision times in milliseconds, as a function of stress and spelling, in Experiment 3. 
At present, these initial studies of orthography and stress cannot place strong constraints on current reading models. In fact, the similarities between our results and those from the phonemic domain encourage broader, rather than narrower, models of reading. However, any drive toward breadth through stress does depend on answers to two questions that we will address further in this discussion. First, to what extent do the orthographic patterns that we have examined and their associated empirical effects actually involve stress? Second, how far can the results be generalized beyond the disyllabic words studied here?

\section{Orthography, Stress, and Vowels}

We have claimed in this paper that delays or failures in word naming and identification can occur when orthography provides misleading information about lexical stress. However, another possible account of our results should be considered. In particular, when words are assigned an incorrect stress, they also receive incorrect vowels. For instance, when cadet is pronounced with its standard iambic stress pattern, its phonemic representation is / kadet/. However, this representation changes to / kædit / when the word is incorrectly pronounced with trochaic stress. Given this confound between stress and vowel quality, we should consider the possibility that the effects in our experiments are due to vowel quality changes rather than to stress.

There are two ways to press this argument, and they differ in the severity of their consequences for relations between orthography and stress. The most extreme position would claim that spelling patterns such as $e t$ and ette do not represent stress at all. Rather they represent vowels, with et generally encoding / $/$ / and ette encoding /e/. Exceptions to these patterns cause processing difficulties, but in the same way that pint is more difficult to process than mint. Under this view, our experiments have not left the domain of phonemic structure at all but simply replicated old results with new materials. The second position would acknowledge that certain spelling patterns are correlated with stress and may indeed have effects on naming performance. However, difficulties in word identification, as measured by lexical decision in Experiment 2, are not caused by incorrect stress assignments but rather by incorrect vowel assignments - in other words, by erroneous phonemic structures. We will consider each of these arguments, beginning with the more extreme position.

Orthography represents vowel quality. If the spelling patterns studied in this paper and elsewhere (e.g., Carney, 1994; Smith et al., 1982; Verrekia \& Kelly, 1996) represent vowel information rather than stress, we would not have to complicate our view of English orthography by claiming that it encodes stress as well as phonemic information. Though appealing for its simplicity, this proposal has many problems. First, the correlation between stress and spelling does not disappear with this move. It remains a fact that -ette is associated with iambic stress and -et with trochaic stress. Such corre- spondences remain unexplained by the vowel quality view, unless one can claim that the stress contrast is carried by vowel differences rather than by orthographic differences. This strategy could work if the spelling difference regularly marked a contrast between full vowels such as /a/and the reduced vowel/a/, since vowel reduction is associated with stress in English (see, e.g., Fear, Cutler, \& Butterfield, 1995). Though this proposal could work for some spelling contrasts, like the difference between the pronunciations of or and ore in gator and galore, it cannot work for many others, as an examination of Table 1 shows.

Second, some spelling distinctions represent exactly the same vowel but are still associated with different stress patterns. Thus $o$ and ea $u$ can represent $/ o /$, but the latter is more likely to appear in iambic words. Similar cases can be made with the $y$-ee, ene-een, and $u$-oo spelling pairs, which map onto the same vowel but different stress patterns. Still, one might respond that, even if the second syllable vowel remains the same across a stress change, the first syllable does not. Thus, if levee is incorrectly read with iambic stress, the vowel in the first syllable will be pronounced as a schwa rather than /e/. Perhaps the $e e$ and other spellings still encode vowels, but the relevant vowel is in the first rather than second syllable.

This option is not appealing, because it would require major changes in our understanding of orthography. In particular, the relationship between graphemic patterns and phonemes is constrained sharply by syllable boundaries. Thus, $p h$ only represents an /f / when the adjacent letters occur within the same syllable. When the $h$ is in a different syllable, as in shepherd, the $p$ represents a $/ \mathrm{p} /$. This principle of syllable dependency would be compromised in proposals that allow graphemes to represent vowels in distant syllables. Furthermore, such a move is not required, since, quite apart from orthography, diverse phonological theories recognize that changes in stress lead to changes in vowels (see, e.g., Chomsky \& Halle, 1968; Selkirk, 1984). Whatever phonological theory succeeds best in relating stress changes to vowel changes, orthographic research will inherit this success for free.

Stress versus vowels in word identification. The discussion in the last section leads to the conclusion that certain spelling patterns in a word can indeed induce a particular stress assignment, which, in turn, contributes to vowel selection. With this relationship between orthography, stress, and vowels as background, we will now discuss the possibility that word identification is driven by phonemic information alone. This position has been advanced by Cutler (1986) on the basis of experiments she performed with words, such as permit and forbear, that can vary in stress but without concomitant vowel changes. These experiments exploited the fact that the different stressed versions of such words have different meanings. Thus, the trochaic version of forbear is a noun meaning ancestor, whereas the iambic version is a verb meaning to be patient. Cutler found that either version primed both meanings and that there was no priming advantage for 
meanings appropriate to a particular stress pattern. Cutler concluded that stress changes unaccompanied by vowel changes would not constrain lexical access. By extension, one might claim that the results from our lexical decision experiment were due to incorrect vowel, rather than stress, assignments.

Although it is based on a null result, we will, for the sake of argument, grant Cutler's (1986) conclusion that vowel quality is a necessary factor in constraining lexical access. However, stress and their associated orthographic cues may still play a critical role in this process. The issue here involves levels of causation. Incorrect vowel assignments could be the proximal reasons for the orthographic effects in our lexical decision experiment, but the distal explanation has to do with stress assignment, in that the vowel errors are caused ultimately by stress assignment errors. So, it may be true that the stress difference on forbear does not affect lexical access because it does not also affect the intermediate level of vowel quality. However, as Cutler herself points out, there are only a handful of such words in English. For almost all English words, a stress difference will create vowel differences and so indirectly affect word identification. The spelling patterns that we have examined here begin the domino effect by encoding stress information.

\section{The Generality of Orthographic Cues to Stress}

Although our experiments focused solely on disyllabic words, they could be extended to longer words, since orthographic cues to stress exist for these words as well. For example, like disyllabic words, most trisyllabic English words have stress on the first syllable, but there are many exceptions. Orthographic cues would be useful in marking trisyllabic words that have atypical stress. Indeed, second syllable stress is reliably marked by letter doubling (e.g., stamina vs. savanna; Carney, 1994). By analogy with our results from disyllabic words, we would predict that trisyllabic words like gorilla would be read more quickly and accurately than words like granola, because the former has a reliable orthographic cue to stress whereas the latter does not. In contrast, words like paraffin should be read more slowly and less accurately than paragon, because the double $f$ in the former case is a misleading cue to stress. Thus, the phenomena that we have examined in this paper could have widespread generality in assigning stress to written words, and so further research in this domain could contribute much to our understanding of reading.

\section{REFERENCES}

CARNEY, E. (1994). A survey of English spelling. London: Routledge Chomsky, N., \& Halle, M. (1968). The sound pattern of English. New York: Harper \& Row.

CUTLER, A. (1986). Forbear is a homophone: Lexical prosody does not constrain lexical access. Language \& Speech, 29, 201-220.

CUTLER, A., \& CARTER, D. M. (1987). The predominance of strong initial syllables in the English vocabulary. Computer Speech \& Language, 2, 133-142.

Fear, B. D., Cutler, A., \& Butterfield, S. (1995). The strong/weak syllable distinction in English. Journal of the Acoustical Society of America, 97, 1893-1904.

FRANCIS, W. N., \& KuČERA, H. (1982). Frequency analysis of English usage: Lexicon and grammar. Boston: Houghton-Mifflin.

Hudson, P. T., \& Bergman, M. W. (1985). Lexical knowledge in word recognition: Word length and word frequency in naming and lexical decision tasks. Journal of Memory \& Language, 24, 46-58.

KELLY, M. H. (1992). Using sound to solve syntactic problems: The role of phonology in grammatical category assignment. Psychological Review, 99, 349-364.

Kelly, M. H., \& Bock, J. K. (1988). Stress in time. Journal of Experimental Psychology: Human Perception \& Performance, 14, 389-403

LofTUs, G. R., \& MASSON, M. E. J. (1994). Using confidence intervals in within-subject designs. Psychonomic Bulletin \& Review, 1, 476-490.

Parkin, A. J. (1982). Phonological recoding in lexical decision: Effects of spelling-to-sound regularity depend on how regularity is defined. Memory \& Cognition, 10, 43-53.

Seidenberg, M. S., \& MCClelland, J. L. (1989). A distributed, developmental model of word recognition and naming. Psychological Review, 96, 523-568.

Seidenberg, M. S., Waters, G. S., Barnes, M. A., \& Tanenhaus, M. K. (1984). When does irregular spelling or pronunciation influence word recognition? Journal of Verbal Learning \& Verbal Behavior, 23, 383-404.

SelKIRK, E. O. (1984). Phonology and syntax. Cambridge, MA: MIT Press.

SMith, P. T., \& BaKER, R. G. (1976). The influence of English spelling on pronunciation. Journal of Verbal Learning \& Verbal Behavior, 15, 267-285.

Smith, P. T., Baker, R. G., \& Groat, A. (1982). Spelling as a source of information about children's linguistic knowledge. British Journal of Psychology, 73, 339-350.

Taraban, R., \& MCClelland, J. L. (1987). Conspiracy effects in word recognition. Journal of Memory \& Language, 26, 608-631.

VENEZKY, R. L. (1970). The structure of English orthography. The Hague: Mouton.

VerReKIA, L., \& Kelly, M. H. (1996). Orthographic information for lexical stress in English. Unpublished manuscript.

WATERS, G. S., \& SEIDENBERG, M. S. (1985). Spelling-sound effects in reading: Time-course and decision criteria. Memory \& Cognition, 13, 557-572. 
APPENDIX A

Words Used in Experiments 1 and 2 Along With Their Frequencies in Francis and Kučera (1982), the Proportion of Classification Errors, and Mean Correct Reaction Times in Milliseconds (RT) in the Naming (N) and Lexical Decision (LD) Tasks

\begin{tabular}{|c|c|c|c|c|c|c|c|c|c|c|c|c|c|}
\hline Word & Category & Frequency & N Errors & N RT & LD Errors & LD RT & Word & Category & Frequency & N Errors & N RT & LD Errors & LD RT \\
\hline Boutique & $\mathrm{MI}$ & 0 & 0 & 521 & 0 & 727 & Carcass & MT & 7 & 0 & 569 & .13 & 751 \\
\hline Baton & UI & 5 & .13 & 606 & .13 & 822 & Carton & UT & 0 & 0 & 569 & .19 & 928 \\
\hline Cassette & MI & 0 & 0 & 561 & 0 & 705 & Charlotte & MT & 13 & 0 & 654 & .13 & 753 \\
\hline Cadet & UI & 4 & 0 & 534 & .06 & 714 & Sherry & UT & 8 & 0 & 557 & .06 & 758 \\
\hline Cocaine & MI & 1 & 0 & 531 & 0 & 747 & Furlough & MT & 2 & 0 & 614 & .19 & 1,090 \\
\hline Collage & UI & 15 & .13 & 615 & .38 & 959 & Furrow & UT & 5 & 0 & 598 & .06 & 761 \\
\hline Cornell & MI & 5 & 0 & 535 & .06 & 735 & Harness & MT & 10 & 0 & 619 & 0 & 760 \\
\hline Canal & UI & 3 & 0 & 619 & 0 & 624 & Hardship & UT & 9 & 0 & 491 & 0 & 761 \\
\hline Corvette & MI & 0 & .06 & 570 & .19 & 723 & Igloo & MT & 0 & 0 & 665 & .06 & 839 \\
\hline Cornet & UI & 0 & .38 & 585 & .31 & 958 & Ingot & UT & 0 & 0 & 691 & .38 & 1,116 \\
\hline Decree & MI & 3 & 0 & 674 & 0 & 937 & Impasse & MT & 2 & .13 & 526 & 0 & 824 \\
\hline Decor & UI & 4 & .06 & 574 & 0 & 753 & Impulse & UT & 20 & 0 & 561 & 0 & 714 \\
\hline Duress & MI & 1 & 0 & 567 & .31 & 867 & Juneau & MT & 0 & .38 & 663 & .44 & 1170 \\
\hline Duet & UI & 1 & 0 & 517 & .06 & 754 & Judo & UT & 0 & 0 & 656 & .06 & 759 \\
\hline Gazzelle & MI & 1 & 0 & 526 & .06 & 858 & Levee & MT & 1 & .38 & 744 & .5 & 986 \\
\hline Guffaw & UI & 0 & .13 & 579 & .50 & 777 & Lever & UT & 13 & 0 & 703 & .06 & 799 \\
\hline Giraffe & MI & 0 & 0 & 589 & 0 & 693 & Mandrill & MT & 0 & .13 & 613 & .44 & 1,037 \\
\hline Gerard & UI & 0 & .25 & 641 & .31 & 934 & Mandrake & UT & 0 & 0 & 652 & .56 & 778 \\
\hline Kazoo & MI & 1 & 0 & 535 & .19 & 849 & Migraine & MT & 0 & 0 & 570 & .06 & 749 \\
\hline Kabob & UI & 0 & 0 & 574 & .38 & 885 & Membrane & UT & 6 & 0 & 595 & .13 & 783 \\
\hline Lacrosse & MI & 0 & 0 & 538 & 0 & 804 & Palette & MT & 5 & .06 & 616 & 0 & 812 \\
\hline Lapel & UI & 1 & 0 & 530 & .13 & 835 & Pellet & UT & 0 & 0 & 657 & .13 & 901 \\
\hline Plateau & MI & 3 & 0 & 637 & .06 & 768 & Radcliffe & MT & 0 & 0 & 555 & .38 & 1,016 \\
\hline Pastel & UI & 3 & .06 & 620 & .06 & 797 & Rosemont & UT & 0 & 0 & 557 & .25 & 1,097 \\
\hline Rosanne & MI & 0 & .06 & 551 & .13 & 772 & Russell & MT & 12 & 0 & 505 & .13 & 836 \\
\hline Rochel & UI & 0 & .06 & 661 & .75 & 1,058 & Ronald & UT & 5 & 0 & 604 & .06 & 750 \\
\hline Shampoo & MI & 2 & 0 & 559 & 0 & 644 & Tepee & MT & 0 & .06 & 619 & .19 & 952 \\
\hline Chiffon & UI & 0 & .06 & 642 & .25 & 938 & Terry & UT & 7 & 0 & 536 & .19 & 735 \\
\hline Suspense & MI & 6 & 0 & 623 & 0 & 706 & Trochee & MT & 0 & .25 & 786 & .63 & 1,022 \\
\hline Sedan & UI & 2 & 0 & 644 & .19 & 858 & Trojan & UT & 0 & 0 & 591 & 0 & 723 \\
\hline Taboo & MI & 1 & 0 & 585 & 0 & 766 & Voodoo & MT & 2 & 0 & 579 & 0 & 908 \\
\hline Tibet & UI & 7 & .19 & 546 & .13 & 851 & Vermin & UT & 0 & 0 & 569 & .06 & 841 \\
\hline
\end{tabular}

Note-Category abbreviations are MI (marked iambic), UI (unmarked iambic), MT (marked trochaic), and UT (unmarked trochaic). For ease of comparisons, words in yoked pairs are arranged consecutively.

\section{APPENDIX B}

Nonwords Used in Experiment 2

Algineet, Anvustry, Aploonshent, Aspiltance, Asteby, Avenuk, Baf, Baft, Bap, Benlury, Bomt, Brench, Carc, Cazeta, Ceft, Cetrital, Cheld, Chorn, Colceptoon, Colsipeen, Conbeecton, Deetushon, Difk, Dilperenck, Diltinksion, Doath, Dompission, Dreel, Dyprogyn, Efiltosh, Efplusmon, Enverprosh, Exiltoork, Fank, Fenalor, Fict, Fipe, Fup, Gake, Goav, Gorp, Gume, Helv, Hemory, Igstrectoon, Ikplueefe, Ilpeerance, Insprukment, Isprellton, Lonsevence, Maib, Momsletion, Mub, Neeshborhuld, Nisht, Obloative, Ollastan, Oquigin, Otrineen, Paft, Palch, Paph, Pegilning, Phafe, Pibrafy, Pleem, Ploor, Prelvury, Prufelpor, Qeek, Quobection, Quon, Rapeklic, Raste, Relistalce, Roke, Rooz, Sarmth, Sercenrage, Sesslevent, Shought, Shreat, Sibe, Slort, Smezz, Sprelm, Tafio, Teav, Themipal, Treen, Tudience, Uxlansion, Veech, Wege, Whulk, Yite, Zye 
APPENDIX C

Words Used in Experiment 3 Along With Their Frequencies in Francis and Kutera (1982), the Proportion of Lexical Decision Errors, and Mean Correct Response Times in Milliseconds (RT)

\begin{tabular}{|c|c|c|c|c|c|c|c|c|c|}
\hline Word & Category & Frequency & Errors & RT & Word & Category & Frequency & Errors & RT \\
\hline Antique & MI & 8 & 0 & 612 & Boycott & MT & 7 & .06 & 696 \\
\hline Bamboo & MI & 0 & 0 & 655 & Bureau & MT & 42 & 0 & 661 \\
\hline Bazaar & MI & 7 & .28 & 635 & Carcass & MT & 7 & .11 & 646 \\
\hline Boutique & MI & 1 & .17 & 660 & Charlotte & MT & 13 & .11 & 691 \\
\hline Burlesque & MI & 1 & .17 & 815 & Cocoa & MT & 2 & 0 & 610 \\
\hline Cassette & MI & 0 & 0 & 593 & Coffee & MT & 78 & 0 & 642 \\
\hline Cocaine & MI & 1 & 0 & 680 & Compass & MT & 12 & .11 & 625 \\
\hline Cornell & MI & 5 & 0 & 596 & Comrade & MT & 4 & 0 & 642 \\
\hline Corvette & MI & 0 & .06 & 629 & Doctrine & MT & 46 & 0 & 722 \\
\hline Decree & MI & 3 & 0 & 712 & Famine & MT & 3 & .06 & 672 \\
\hline Degree & MI & 125 & 0 & 599 & Furlough & MT & 2 & .28 & 838 \\
\hline Distress & MI & 15 & .06 & 687 & Harness & MT & 10 & .06 & 689 \\
\hline Duress & MI & 1 & .28 & 785 & Igloo & MT & 0 & 0 & 786 \\
\hline Gazelle & MI & 1 & .06 & 679 & Impasse & MT & 2 & .22 & 700 \\
\hline Giraffe & MI & 0 & 0 & 619 & Juneau & MT & 0 & .28 & 853 \\
\hline Lacrosse & MI & 0 & .06 & 701 & Migraine & MT & 0 & .06 & 701 \\
\hline Michelle & MI & 0 & 0 & 650 & Omelette & MT & 0 & 0 & 656 \\
\hline Plateau & MI & 3 & .06 & 714 & Palette & MT & 5 & 0 & 765 \\
\hline Rosanne & MI & 0 & .11 & 657 & Radcliffe & MT & 0 & .22 & 804 \\
\hline Roulette & MI & 4 & 0 & 669 & Russell & MT & 12 & .11 & 654 \\
\hline Seville & MI & 0 & .06 & 761 & Sheriff & MT & 20 & 0 & 655 \\
\hline Shampoo & MI & 2 & 0 & 629 & Tariff & MT & 5 & .11 & 686 \\
\hline Taboo & MI & 1 & .06 & 623 & Tepee & MT & 0 & .33 & 721 \\
\hline Trustee & MI & 9 & .06 & 714 & Voodoo & MT & 2 & .11 & 702 \\
\hline Baton & UI & 5 & .06 & 731 & Basin & UT & 7 & .06 & 756 \\
\hline Berlin & UI & 76 & .06 & 606 & Bonnet & UT & 3 & .06 & 661 \\
\hline Bernard & UI & 9 & .06 & 677 & Bubble & UT & 12 & 0 & 604 \\
\hline Brazil & UI & 8 & 0 & 656 & Carton & UT & 0 & .06 & 624 \\
\hline Cadet & UI & 4 & .11 & 675 & Chorus & UT & 18 & 0 & 588 \\
\hline Canal & UI & 3 & .06 & 618 & Circus & UT & 7 & .06 & 624 \\
\hline Cartel & UI & 0 & .06 & 741 & Falcon & UT & 4 & 0 & 675 \\
\hline Chagrin & UI & 4 & .11 & 792 & Guru & UT & 1 & .17 & 726 \\
\hline Cigar & UI & 10 & 0 & 561 & Halo & UT & 2 & .17 & 768 \\
\hline Cornet & UI & 0 & .17 & 688 & Hindu & UT & 3 & 0 & 710 \\
\hline Decor & UI & 4 & .06 & 714 & Judo & UT & 0 & .06 & 612 \\
\hline Duet & UI & 1 & 0 & 631 & Kettle & UT & 3 & .06 & 623 \\
\hline Exam & UI & 0 & 0 & 584 & Membrane & UT & 6 & .06 & 648 \\
\hline Fondu & UI & 0 & .22 & 766 & Menu & UT & 5 & 0 & 571 \\
\hline Guitar & UI & 19 & .06 & 631 & Pellet & UT & 0 & .17 & 680 \\
\hline Japan & UI & 38 & 0 & 582 & Plato & UT & 20 & 0 & 656 \\
\hline Kabob & UI & 0 & .44 & 867 & Salad & UT & 9 & 0 & 582 \\
\hline Lapel & UI & 1 & .17 & 730 & Susan & UT & 37 & 0 & 661 \\
\hline Motel & UI & 24 & .06 & 659 & Taxi & UT & 16 & 0 & 543 \\
\hline Motif & UI & 8 & .28 & 648 & Terry & UT & 7 & 0 & 662 \\
\hline Pastel & UI & 3 & 0 & 727 & Trojan & UT & 0 & .11 & 631 \\
\hline Peru & UI & 4 & .06 & 647 & Turtle & UT & 8 & 0 & 685 \\
\hline Sedan & UI & 2 & .06 & 741 & Velvet & UT & 4 & 0 & 570 \\
\hline Tibet & UI & 7 & .22 & 667 & Virus & UT & 13 & 0 & 681 \\
\hline
\end{tabular}

Note-Category abbreviations are MI (marked iambic), UI (unmarked iambic), MT (marked trochaic), and UT (unmarked trochaic).

(Manuscript received August 14, 1996;

revision accepted for publication April 28, 1997.) 